\title{
A STUDY OF MATERNAL PERCEPTION OF DECREASED FOETAL MOVEMENT AND PERINATAL OUTCOIME
}

\section{Dr. Nitesh Meena}

Senior Resident, Department Of Obstetrics And Gynecology, J.k. Lone Hospital, Kota, Rajasthan, India

Dr. Suhail Iqbal

\section{Dr. Heena}

Kaurani*
Senior Resident, Department Of Obstetrics And Gynecology, Government Medical College, Baramulla, Jammu And Kashmir, India

Senior Resident, Department Of Obstetrics And Gynecology, Dr. Sampurnan And Medical College, Jodhpur, Rajasthan, India. *Corresponding Author

BACKGROUND: Fetal movement is described as motion of the fetus perceived by the mother and is considered as a sign of foetal wellbeing. A reduction of foetal movements causes concern and anxiety, both to the mother and obstetrician. Decreased foetal movements are regarded as a marker for suboptimal intrauterine conditions, possibly of placental dysfunction and intrauterine stress. Evaluation of maternal perception of decrease foetal movement is done by taking proper history, daily foetal movement count (DFMC), non-stress test (NST) and ultrasonography.

AIM AND OBJECTIVES: The aim of this study was to find out perinatal outcome among women with decreased foetal movements. The rational for the study is that our findings should contribute to maternal understanding of foetal wellbeing in utero, and possible ways to work with mothers to prevent intrauterine foetal deaths and stillbirths.

MATERIAL AND METHODS: This is a hospital based descriptive study conducted at Obstetrics and Gynaecology department, Srimati Heera Kunwar Ba Mahila Chikitsalaya, Jhalawar Medical College Jhalawar from November 2018 to October 2019. Ethical approval was taken from ethical committee and written informed consent was taken from the participants. Total 192 women were included in the study with complain of decreased foetal movements. To ev aluate the foetal well-being daily foetal movement count (DFMC), non-stress test (NST) and ultrasonography was done. RESULT: There was no statistically significant association between DFMC and foetal outcome, but reactive NST is associated with good foetal outcome.

CONCLUSION: We conclude that reduced foetal movement during $3^{\text {rd }}$ trimester could be ominous sign. Our study suggests that NST, sonography and DFMC may be used to evaluate the women complaining of decrease foetal movement and may identify the women at risk for adverse perinatal outcome.

\section{INTRODUCTION}

"No matter how hard my day has been, all it takes is one little kick to make everything feel alright." There is no better feeling for a woman than the movement of life inside her. Foetal movement is described as motion of the foetus perceived by the mother and felt by palpation of the abdomen by others. This is one of the first sign of foetal life and adequate foetal movements are considered as sign of foetal wellbeing. ${ }^{1,2}$ Most of the pregnant women usually perceive foetal movements from around 20 weeks gestation with a peak at 28-34 weeks gestation. ${ }^{3}$ The number of spontaneous movements tend to increase until the 32 nd week of pregnancy. From this stage of gestation, the frequency of foetal movements plateaus until the onset of labour. Multiparous women may notice movements earlier (16-20 weeks gestation) than primiparous women (20-22 weeks) gestation ${ }^{1}$. Foetal movement follow a circadian pattern and are an expression of foetal wellbeing. A reduction of foetal movements causes concern and anxiety, both to the mother and obstetrician. Reduced foetal movement is difficult to interpret because it is a subjective complaint by the mother. Decreased foetal movements are regarded as a marker for suboptimal intrauterine conditions, possibly of placental dysfunction and intrauterine stress. The foetus responds to chronic hypoxia by conserving energy and the subsequent reduction of foetal movement is an adaptive mechanism to reduce oxygen consumption. It is well known that in many cases an intrauterine death (IUD) is preceded by cessation of foetal movement for at least 24 hours. ${ }^{4}$ Conditions associated with diminished foetal movements are intrauterine foetal death (IUD), foetal sleep, foetal position, foetal congenital malformation, foetal anaemia or hydrops, reduced amniotic fluid volume, small for gestational age foetus (SGA)/ intrauterine growth restriction (IUGR), polyhydramnios, increased maternal weight, anterior placental localisation, maternal sedating drugs which cross the placenta (alcohol, benzodiazepines, barbiturates, methadone and narcotics),smoking, administration of corticosteroids for promotion of foetal lung maturity, a busy mother who is not concentrating on foetal activity, maternal anaemia, metabolic disorders, hypothyroidism acute or chronic feto- maternal haemorrhage. Evaluation of maternal perception of decrease foetal movement is done by taking proper history, daily foetal movement count (DFMC), non-stress test (NST) and ultrasonography. The aim of this study was to find out perinatal outcome among women with decreased foetal movements. The rational for the study is that our findings should contribute to maternal understanding of foetal wellbeing in utero, and possible ways to work with mothers to prevent intrauterine foetal deaths and stillbirths.

\section{MATERIAL AND METHODS:}

This is a hospital based descriptive study conducted at Obstetrics and Gynaecology department, Srimati Heera Kunwar Ba Mahila Chikitsalaya, Jhalawar Medical College Jhalawar from November 2018 to October 2019.

\section{Sample Size: -}

Sample size is calculated at $95 \%$ confidence level assuming occurrence of adverse perinatal outcome in $20 \%$ pregnant mothers with decreased foetal movements as per the results of seed article. For allowing error of $5 \%$ minimum 160 patients are required as sample. This was taken as rounded of 192 patients assuming $20 \%$ dropout rate/admission. The sample size was calculated by following formula:

$$
\mathrm{N}=\mathrm{t}^{2} * \mathrm{p}(1-\mathrm{p}) / \mathrm{e}^{2}
$$

\section{n-required sample size}

t- standard normal deviate at $95 \%$ confidence interval $\mathrm{p}$ - estimated proportion of pregnant mother with decreased foetal movements.

e- estimated margin of error or level of significance $=5 \%$ substituting the value, $\mathrm{n}=192$ (approx....)

Inclusion Criteria: - Singleton pregnancy (28-40 weeks) with cephalic presentation. 
Exclusion Criteria: -Females with obstetrical complications such as pregnancy induced hypertension, eclampsia, abnormal foetal presentation, multi-foetal pregnancy, medical disorders such as Diabetes Mellitus, thyroid disorder, hypertension, and severe anaemia.

METHOD: - Patients presenting with decreased foetal movements was evaluated by taking detailed history, clinical examination, DFMC, non-stress test and ultrasonography.

DFMC: Patients were asked to draw a line on paper whenever she perceives foetal movement in one hour. Total foetal movements in 12 hours were counted and if it was less than 10 than it was considered as decreased foetal movement.

Non stress test- Procedure: The ultrasound (foetal heart rate) transducer was belted on the lower abdomen at a site from where the FHS was most distinctly audible after applying an aqua sonic jelly. The Toco transducer was belted on the upper abdomen over the uterine fundus so that it can easily detect the anterior deflection of the uterus that occurs during a contraction. The event marker was held by the patient, and she was instructed to press the button with each foetal movement. The NSTs were classified into 2 groups based on the presence or absence of at least 2 FHR - accelerations of 15 bpm lasting for 15 seconds in a 20 -minute reading into-

1) Reactive or normal test or reassuring test

2) Non-reactive or abnormal test or non-reassuring test

Ultrasonography - Ultrasound scan was done for the assessment of placental localisation, amniotic fluid volume, estimated gestational age, estimated foetal weight, position of cord (nuchal or non-nuchal).

\section{RESULT:}

Table 1 shows particulars of the patients. The mean age of the study group was $27.24 \pm 3.56$ years (range $20-30$ year. Most of them $(93.7 \%)$ belong to $26-30$ years of age groups. Table 2 shows relation of different parameters with DFMC and no statistically significant association with foetal well-being and foetal outcome. Table 3 shows statistically significant association of NST with foetal outcome.

Table 1: Patient's particulars

\begin{tabular}{|l|l|c|c|}
\hline \multicolumn{2}{|l|}{ Particulars } & Number & Percentage \\
\hline Age (Years) & $20-25$ & 12 & 6.2 \\
\cline { 2 - 4 } & $26-30$ & 180 & 93.7 \\
\hline \multirow{3}{*}{ Religion } & Hindu & 166 & 86.5 \\
\cline { 2 - 4 } & Muslim & 26 & 13.5 \\
\hline \multirow{2}{*}{ Location } & Urban & 108 & 56.3 \\
\cline { 2 - 4 } & Rural & 84 & 43.7 \\
\hline \multirow{2}{*}{ Parity } & Primi & 113 & 58.85 \\
\cline { 2 - 4 } & Multi & 79 & 41.15 \\
\hline
\end{tabular}

Table 2: Relation of DFMC with different parameters

\begin{tabular}{|c|c|c|c|c|}
\hline Parameter & & \begin{tabular}{|l|} 
Decreased \\
DFIMC \\
\end{tabular} & $\begin{array}{l}\text { Normal } \\
\text { DFIMC } \\
\end{array}$ & \begin{tabular}{|l|}
$P$ \\
value
\end{tabular} \\
\hline Non stress & Reactive & $94(81.03 \%)$ & $60(78.04 \%)$ & 0.7226 \\
\hline test (NST) & Non-reactive & $22(18.96 \%)$ & $16(21.05 \%)$ & \\
\hline Cord & Present & $10(8.69 \%)$ & $8(10.38 \%)$ & 692 \\
\hline $\begin{array}{l}\text { around } \\
\text { neck(CAN) }\end{array}$ & Absent & $105(91.30 \%)$ & $69(89.61 \%)$ & \\
\hline Amniotic & $<5$ & $6(5.2 \%)$ & $5(6.4 \%)$ & 0.709 \\
\hline $\begin{array}{l}\text { fluid } \\
\text { index(AFI) }\end{array}$ & $>5$ & $109(94.7 \%)$ & $72(93.5 \%)$ & \\
\hline Meconiu & Present & $6(5.21 \%)$ & $3(3.89 \%)$ & 0.671 \\
\hline $\begin{array}{l}\text { m-stained } \\
\text { liquor } \\
\text { (MSL) }\end{array}$ & Absent & $109(94.78 \%)$ & $74(96.10 \%)$ & \\
\hline Mode of & \begin{tabular}{|l|} 
Normal \\
\end{tabular} & $34(29.56 \%)$ & $21(27.27 \%)$ & 0.7306 \\
\hline & LSCS & $81(70.43 \%)$ & $56(72.72 \%)$ & \\
\hline
\end{tabular}

www.worldwidejournals.com

\begin{tabular}{|l|l|l|l|l|}
\hline Birth & $<2.5$ & $30(26.08 \%)$ & $20(25.97 \%)$ & 1 \\
weight(kg) & $>2.5$ & $85(73.91 \%)$ & $57(74.02 \%)$ & \\
\hline \multirow{2}{*}{$\begin{array}{l}\text { NICU } \\
\text { admission }\end{array}$} & Yes & $44(32.26 \%)$ & $30(38.96 \%)$ & 0.9203 \\
\cline { 2 - 4 } $\begin{array}{l}\text { Foetal } \\
\text { outcome }\end{array}$ & Good(alive) & $109(91.73 \%)$ & $47(61.03 \%)$ & \\
\cline { 2 - 4 } & Poor (Dead) & $6(5.21 \%)$ & $75(97.40 \%)$ & 0.3732 \\
\hline
\end{tabular}

Table 3: Relation of NST with different parameters

\begin{tabular}{|c|c|c|c|c|}
\hline \multicolumn{2}{|l|}{ Parameter } & \multirow{2}{*}{\begin{tabular}{|l|}
$\begin{array}{l}\text { Reactive } \\
\text { NST }\end{array}$ \\
60 \\
$(78.94 \%)$
\end{tabular}} & \multirow{2}{*}{\begin{tabular}{|l|}
$\begin{array}{l}\text { Non- } \\
\text { reactive } \\
\text { NST }\end{array}$ \\
16 \\
$(21.05 \%)$
\end{tabular}} & \multirow{3}{*}{\begin{tabular}{|l|}
$\begin{array}{l}\mathbf{P} \\
\text { value }\end{array}$ \\
0.7226 \\
\end{tabular}} \\
\hline \multirow[t]{2}{*}{ DFIMC } & Normal & & & \\
\hline & Decreased & $\begin{array}{l}94 \\
(81.03 \%)\end{array}$ & $\begin{array}{l}22 \\
(18.96 \%)\end{array}$ & \\
\hline \multirow{2}{*}{$\begin{array}{l}\text { Cord around } \\
\text { neck (CAN) }\end{array}$} & Present & $8(32 \%)$ & $17(68 \%)$ & \multirow[t]{2}{*}{$<0.0001$} \\
\hline & \begin{tabular}{|l} 
Absent \\
\end{tabular} & \begin{tabular}{|l|}
146 \\
$(87.42 \%)$
\end{tabular} & \begin{tabular}{|l|}
21 \\
$(12.57 \%)$
\end{tabular} & \\
\hline \multirow{2}{*}{$\begin{array}{l}\text { Amniotic } \\
\text { fluid index } \\
\text { (AFI) }\end{array}$} & $<5$ & $\begin{array}{l}11 \\
(42.30 \%)\end{array}$ & $\begin{array}{l}15 \\
(57.69 \%)\end{array}$ & \multirow[t]{2}{*}{$<0.0001$} \\
\hline & $>5$ & $\begin{array}{l}142 \\
(85.54 \%)\end{array}$ & $\begin{array}{l}24 \\
(14.45 \%)\end{array}$ & \\
\hline \multirow{2}{*}{$\begin{array}{l}\text { Meconium- } \\
\text { stained } \\
\text { liquor (MSL) }\end{array}$} & Present & 0 & $\begin{array}{l}8 \\
(20.51 \%)\end{array}$ & \multirow[t]{2}{*}{$\left.\right|_{*} ^{<0.0001}$} \\
\hline & \begin{tabular}{|l} 
Absent \\
\end{tabular} & \begin{tabular}{|l}
153 \\
$(100 \%)$
\end{tabular} & \begin{tabular}{|l|}
31 \\
$(79.48 \%)$
\end{tabular} & \\
\hline \multirow[t]{2}{*}{$\begin{array}{l}\text { Mode of } \\
\text { delivery }\end{array}$} & Normal & $\begin{array}{l}55 \\
(35.94 \%) \\
\end{array}$ & 0 & \multirow[t]{2}{*}{$<0.0001$} \\
\hline & LSCS & $\begin{array}{l}98 \\
(64.05 \%) \\
\end{array}$ & $39(100 \%)$ & \\
\hline \multirow[t]{2}{*}{$\begin{array}{l}\text { Birth weight } \\
\text { (lkg) }\end{array}$} & $<2.5$ & $\begin{array}{l}40 \\
(25.97 \%)\end{array}$ & \begin{tabular}{|l}
10 \\
$(26.31 \%)$
\end{tabular} & \multirow[t]{2}{*}{0.8962} \\
\hline & $>2.5$ & $\begin{array}{l}114 \\
(74.02 \%)\end{array}$ & $\begin{array}{l}27 \\
(71.05 \%)\end{array}$ & \\
\hline \multirow[t]{2}{*}{$\begin{array}{l}\text { NICU } \\
\text { admission }\end{array}$} & Yes & $\begin{array}{l}74 \\
(38.54 \%)\end{array}$ & $38(100 \%)$ & \multirow[t]{2}{*}{$0.0001^{*}$} \\
\hline & No & $\begin{array}{l}118 \\
(61.45 \%)\end{array}$ & 0 & \\
\hline \multirow[t]{2}{*}{$\begin{array}{l}\text { Foetal } \\
\text { outcome }\end{array}$} & Good (Alive) & \begin{tabular}{|l}
152 \\
$(98.70)$ \\
\end{tabular} & \begin{tabular}{|l|}
32 \\
$(84.21 \%)$
\end{tabular} & \multirow[t]{2}{*}{$<0.0001$} \\
\hline & Poor (Dead) & $2(1.29 \%)$ & $6(15.78 \%)$ & \\
\hline
\end{tabular}

\section{DISCUSSION}

A perception of reduced foetal movements is a common complaint by pregnant women. As part of routine antenatal care for many years pregnant women have been advised to note foetal movements in the third trimester. In this study majority of the women $180(93.7 \%)$ were aged between 25 to 30 years. The study group was analysed according to religion. Majority of the women $166(86.5 \%)$ belong to Hindu religion. Most of the women 108 (56.3\%) in this study belong to urban area. The study group was analysed according to parity majority of the women were primigravida 113 (58.8\%). This was similar to the study conducted by Nor Azlin et $\mathrm{al}^{5}$ in which majority of patients with decrease foetal movement were primigravida. Similar finding was also reported by study conducted by Holm Tveit et $\mathrm{al}^{6}$. This is likely due to being less experienced and more willing to seek an explanation with regards to what was perceived to be normal compared with multipara and grand multipara. Study done by Aparna Hedge et $\mathrm{al}^{7}$ the incidence of vaginal delivery in reactive group was $90.5 \%$ and in suspicious group $78.9 \%$ and in ominous group $33.3 \%$. In her study $3 \%$ reactive group, $5.3 \%$ suspicious group and $0 \%$ in ominous group had instrumental delivery and the no. of patients who underwent LSCS in the study was $6.5 \%$ in reactive $15.8 \%$ in equivocal and $66.7 \%$ in ominous group. In another study by Ingemarson, ${ }^{8}$ out of 1041 patients, $81.2 \%$ had vaginal delivery in reactive group and $83.6 \%$ in suspicious group and $50 \%$ in ominous group. In his study, $11.1 \%$ in reactive group, $6.1 \%$ in suspicious group and $0 \%$ in 
ominous group had instrumental delivery. $7.8 \%$ LSCS were done in reactive group $10.8 \%$ in suspicious group, $20 \%$ in ominous group. Regarding the mode of delivery in Vinita Das et al, ${ }^{9}$ study $45.7 \%$ caesarean section was done in reactive group and out of this only $24 \%$ patients has LSCS done for foetal distress, while in patients with abnormal admission test $60.97 \%$ had LSCS and out of this $47.8 \%$ patients had LSCS for foetal distress during labour. This study had included both high and low risk patients. In our study in non-reactive NST, mode of delivery was LSCS in $100 \%$ cases and in reactive NST, mode of delivery was LSCS in $64.05 \%$ cases and ND in $35.94 \%$ cases. In relation to meconium in the study of Ingemarson et $\mathrm{al}^{8}$, thin meconium stain liquor was seen in $6.8 \%$ patients. Thick meconium was detected in $2.8 \%$ patients. Thick meconium was more common in the group with ominous admission test than that of reactive group. So, they reported a poor outcome if thick meconium is associated with other signs to foetal distress e.g., ominous FHR deceleration. In the present study, in non-reactive NST, meconium was absent in $79.48 \%$ cases and present in $20.51 \%$ cases and in reactive NST meconium was absent in $100 \%$ cases. Significant difference was observed between NST, and CAN. Proportion of CAN positive cases were significantly higher in NR NST as compared to reactive. According to Dhungana et $\mathrm{al}^{10}$ the rate of LSCS was higher in patients with decreased foetal movement as compared to patient with good foetal movements. There were $30 \%$ cases of caesarean section in patient with reduced foetal movement as compared to patient with good foetal movements in which rate of caesarean section was $15 \%$. In this study no significance association was found between DFMC and mode of delivery. Study conducted by Dhungana et $\mathrm{al}^{10}$ also not found any significant association between meconium-stained liquor and decreased foetal movement. In this study no significance difference was observed between DFMC and meconium-stained liquor. In the study of Dhungana et al, ${ }^{10}$ they did not found significant association between decrease foetal movement and nuchal cord. In our study no significance difference was present between DFMC and nuchal cord. The study group was analysed according to the birth weight. The patients with decrease DFMC, LBW babies were present in $26.08 \%$ cases and the patients with normal DFMC LBW babies were present in $25.97 \%$ cases. Nor Azlin et $\mathrm{al}^{5}$ found LBW in $6.9 \%$ cases in their study. Study by Sinha et $\mathrm{al}^{11}$ also found IUGR in $19 \%$ of infants in reduced foetal movements. Significance difference was observed between NST and CAN in USG finding.

Proportion of CAN positive cases were significantly higher in NR NST as compared to reactive. The study group was analysed according to AFI in USG finding significant difference was observed between NST and AFI in USG finding. Proportion of AFI <5 (oligo) cases were significantly higher in NR NST as compared to reactive. There was no significant difference between DFMC and nuchal cord in USG finding. Study conducted by Nor Azlin et $\mathrm{al}^{5}$ shows that AFI was normal in $97 \%(n=223)$ of women, while the remaining $3 \%$ $(n=7)$ had oligohydramnios. Dhungana et $\mathrm{al}^{11}$ found $16 \%$ cases of oligohydramnios in patient with decrease foetal movement. In our study no significant difference was observed between DFMC and Oligo ( $<5 \mathrm{AFI}$ ) in USG finding. In the study of Ingemasrsone et $\mathrm{al}^{8},{ }^{8}$ in non-reactive group 9 babies were kept in NICU for observation for 1-2 days. One baby had meconium aspiration syndrome and other baby had HIE Gr.II. In Equivocal group, 18 were taken to NICU, 12 babies were kept in NICU for observation for 1-2 days and one baby had meconium aspiration syndrome. In our study in nonreactive NST NICU admission was in 100\% cases. A normal CTG has been shown to correlate with favourable outcomes in patients who present with reduced foetal movements in the study conducted by Daly et al. In the study of Nor Azlin et al ${ }^{5}$ only $3.5 \%$ neonate admission to NICU. In the study of Sinha et $\mathrm{al}^{11}$ also found NICU admission \& good outcome of infants. In our study no significant difference was observed between DFMC and NICU admission. Grant et $\mathrm{al}^{12} 1989$ studied on
68,000 women with reduced foetal movement and they were unable to demonstrate a reduction in the incidence of antepartum foetal death using daily foetal movement counting. According to them there is no significant association between DFMC and foetal outcome. In our study early neonatal death was $4.16 \%$. According to study conducted by Dhungana et $\mathrm{al}^{10}$ there was only $1 \%$ early neonatal death in patients with decreased foetal movement. In our study no significant difference was observed between DFMC and foetal outcome.

\section{CONCLUSION:}

So, we conclude that reduced foetal movement during $3^{\text {rd }}$ trimester could be ominous sign. Our study suggests that NST, sonography and DFMC may be used to evaluate the women complaining of decrease foetal movement and may identify the women at risk for adverse perinatal outcome.

\section{REFFERENCES}

1. Mar sal K.Ultrasonic assessment of fetal activity.Clin Obstet Gynaecol 1983; 10:541-63.

2. RayburnWF. Fetal body movement monitoring. Obstet Gynaecology Clin North America 1990; $17: 95-110$

3. RayburnWF. Fetal body movement monitoring. Obstet Gynaecology Clin North America 1990; $17: 95-110$

4. Neldam S. Fetal movements. A comparison between maternal assessment and registration by means of dynamic ultrasound.Dan Med Bull 1982;29:197-199

5. Nor AzlinMI,MaisarahAS,Rahana AR,Shafiee MN,AqmarSuraya S, Abdul Karim AK, Jamil MA.Pregnancy outcomes with a primary complaint of perception of reduced fetalmovements.Journal of Obstetrics and Gynaecology. 2015 Jan 2;35(1):13-5.

6. Holm Tveit JV,Saastad E, STRAY,PEDERSEN BA, Børdahl PE, Frøen JF. Maternal characteristics and pregnancy outcomes in women $\mathrm{p}$ re s e $\mathrm{nt}$ ing with decreased fetal movements in late pregnancy. Acta $0 \mathrm{~b} s \mathrm{t}$ e $\mathrm{tr}$ i c i a $\mathrm{e}$ gynecological Scandinavica. 2009 Dec;88(12):1345-51.

7. Hegde Aparna, Kore Shailesha, ShriKrishna Sushma et al. Admission test : screening test for prediction of fetal outcome in labour. JObstest $\mathrm{G}$ y $\mathrm{n}$ a e c India $2001 ; 51(2): 40-43$.

8. Ingemarson I et al Admission test ; Screening test for fetal dsitressin labour. Obstet Gynecol $1986 ; 68: 800-806$.

9. DasVinita,Katiyar Nidhi,Malik GK.Role of admission test J Obstet Gynaec $2002 ; 51$ (1) $48-50$.

10. Dhungana PR,Adhikari R,Pageni PR, Koirala A.Decreased fetal movement: Is it an alarm to Obstetrician and Pregnant Lady?.Medical Journal of Pokhara Academy of Health Sciences. 2018Dec 31;1(2):92-7.

11. Sinha D Sharma. Obstetric outcome in women complaining of reduced $f$ e $t$ a $l$ movements.J. Obstet Gynecol2007;2741-43.

12. Grant E.Elbourne D,Valentin L\&Alexander S. (1989) Routine formal f e t a 1 movement counting and risk of antepartum late death in normally formed singletons.Lancet. 12 ;2 (8659) :345-349. 